\section{A obra didática de Lourenço Filho para o ensino de aritmética/ matemática: uma análise da produção acadêmica}

\section{Lourenço Filho's didactic work for arithmetics/mathematics teaching: an academic production analysis}

\section{Resumo}

O objetivo do presente trabalho é indicar como a produção acadêmica avalia o caráter renovador da obra didática de Lourenço Filho voltada ao ensino de aritmética/matemática, captando as vertentes teóricas que orientam as análises, os pontos de aproximação e as divergências presentes em seu conjunto de produções, além das lacunas, que sugerem novos estudos. A discussão toma por referência estudos de Alves sobre a organização do trabalho didático.

Palavras-Chave: Manual Didático, Aritmética, Lourenço Filho, Escola Nova, Trabalho Didático.

\section{Abstract}

The objective of this work is to indicate how the academic production evaluates the renovating character of Lourenço Filho's didactic work focused on Arithmetic/Mathematics teaching, capturing the theoretical strands that guide the analyzes, interrelated topics, as well as divergences present in their set of productions, besides the gaps, which suggest new studies. The discussion takes as reference Alves' studies on the didactic work organization.

Keywords: Didactic Manual, Arithmetic, Lourenço Filho, New School, Didactic Work.
Prof. ${ }^{a}$ Dr. ${ }^{a}$ Samira Saad

Pulchério Lancillotti

Doutora em Educação (História e Filosofia da Educação) pela Universidade Estadual de Campinas (Unicamp), mestre em Educação pela Universidade Federal de Mato Grosso do Sul (UFMS) e pesquisadora e professora titular também nessa mesma universidade.

E-mail: samira@uems.br

Prof. Helkerr Velasquez Pereira

É pedagogo.

E-mail: helkerr23@gmail.com 


\section{Introdução}

Na virada do século XVIII para o século XIX acontecimentos de cunho global mudaram definitivamente o curso da estrutura econômica mundial consolidando o que viria a ser, a partir de então, a nova forma de organização e o novo modo de produção da sociedade; a saber: o sistema capitalista.

No cenário de transformações mundiais surge, nos Estados Unidos e em países avancados da Europa, no final do século XIX, o movimento denominado Escola Nova, tendo como objetivo a mudança nos modos de ensinar, diante de todas as transformações que o capitalismo, na época já dominante, imputava à sociedade.

Pautado em concepções liberais, o movimento escolanovista fazia duras críticas ao sistema educacional predominante, descrevendo-o como incompatível com o contexto social do período, marcado por industrialização e crescente urbanização. Esses reformadores iniciaram, então, uma ampla disseminação de suas ideias acerca do fazer educacional.

No Brasil, Manoel Bersgström Lourenço Filho (1897-1970) foi um dos principias defensores do movimento da Escola Nova e, baseado nesse ideário educacional, produziu uma gama de manuais didáticos tanto para leitura e alfabetização, quanto para o ensino de aritmética/matemática.

Neste trabalho, buscaremos analisar as produções acadêmicas (artigos, dissertações e teses) que se ocupam do material produzido por Lourenço Filho para o ensino de aritmética/ matemática, no intuito de apreender como os autores abordam esses instrumentos didáticos no âmbito do pensamento reformador a que o autor se filiava. Parte-se do princípio de que há divergência entre a proposta escolanovista e o uso de materiais didáticos uniformes e prescritivos. A discussão toma por base estudos sobre a organização do trabalho didático (ALVES, 2004, 2005; LANCILLOTTI, 2017).

\section{Escola Nova Para Um Novo Tempo}

O movimento escolanovista emergiu com críticas agudas ao sistema educacional predominante. Baseados no princípio de que "educação é vida", os intelectuais norte-americanos John Dewey (1859-1952) e Willian Heard Kilpatrick (1871-1965) ' foram as principais referências internacionais do movimento. Defenderam novos princípios e organização para a educação, compatíveis com as rápidas mudanças mundiais advindas dos avanços do capitalismo, pois entendiam que o progresso, àquela altura, era irrefreável, em virtude dos resultados que a industrialização proporcionara à sociedade.

Kilpatrick sintetizou as tendências observadas nos termos seguintes:

\begin{abstract}
Qualquer estudo da vida moderna revela, desde logo, três profundas tendências: a) uma nova atitude mental, diante da vida; b) a industrialização; e, c) a democracia. Consideradas de um primeiro ponto de vista, parecem todas nascer, pelo menos, em seus aspectos gerais, do pensamento baseado na experimentação [...] De certo modo serão, talvez, na realidade, mais aspectos particulares que realmente tendências diversas. Pelo menos, foram modificadas, e, em alto grau, pela natureza desse pensamento. Consideradas de outro ponto de vista, são elas que obrigam a educação moderna a satisfazer exigências mais definidas. (KILPATRICK, 1947, p. 21)
\end{abstract}

Nesse contexto de embate, entre educação nova e "tradicional", o movimento reformador se expandiu com o discurso de que era neces-

1 John Dewey foi pioneiro do movimento escolanovista nos Estados Unidos, filósofo e pedagogo, representante da corrente pragmatista. Foi um crítico da educação de seu tempo, defendeu uma educação centrada no aluno, guiada por seus interesses, atividade e experiência reconstrutiva. William Heard Kilpatrick, colaborador de Dewey, destacou-se como um dos que tentariam responder de maneira prática aos desafios postos pelo pensamento escolanovista, atuou no sentido de dar uma formulação didática a ele com a proposição do Método de Projetos. 
sário corrigir, ajustar, economizar e ordenar as experiências educativas; que a educação centralizada na figura do professor precisava ser superada, cabendo colocar o aluno no centro do processo educativo, de modo que a escola passaria a considerar seus interesses, conhecimentos prévios, suas aptidões, bem como suas experiências pessoais.

Kilpatrick (1947) argumentou que, enquanto a vida era simples, a criança aprendia na família, no transcurso das atividades cotidianas e no trabalho, de onde vinha tudo o que dizia respeito à vida. Contudo, a realidade havia mudado, uma vez que os pais precisavam trabalhar para assegurar o sustento da família. Nesse contexto, a tarefa de preparar as crianças para o futuro e para os novos desafios da vida, que outrora era papel da família, passou a ser responsabilidade da escola.

Na visão do autor, a educação do futuro deveria ser baseada não mais no autoritarismo da educação tradicional, mas, agora, na democracia. Para Kilpatrick (1947, p. 50), esse caminho era novo e precisava ser aprendido "[...] se quisermos aprender democracia, devemos praticá-la [...] é caminho novo, inçado de dificuldades, mas é o caminho."

Ainda segundo esse autor, as crianças deveriam entender a realidade e as necessidades da civilização que as cercava e, para isso, tudo precisava mudar. Como afirmava: "[...] a mudança tem sido rápida demais para que continue por mais tempo esquecida..." (KILPATRICK, 1947, p. 53).

Esse discurso sobre a necessidade de mudanças para a educação não ficou adstrito à nação norte americana, também ganhou corpo na Europa $^{2}$ e se expandiu para os demais continentes em concomitância com o estabelecimento dos sistemas nacionais de educação.

\section{Escola Nova no Brasil}

O movimento da Escola Nova chegou ao Brasil por volta da década de 1920, tendo entre

2 Há que se destacar, dentre outros, os trabalhos de Édouard Claparède (1873-1940) e Adolph Ferrière (1879-1960), no Instituto Jean Jacques Rousseau, na Suíça; Maria Montessori (1870- 1952), na Itália. os precursores mais destacados Anísio Teixeira (1900-1971), Fernando de Azevedo (1894-1974) e Manoel Bergström Lourenço Filho (1897-1970). É importante ressaltar que, nas duas primeiras décadas do século $X X$, o ensino público no Brasil não tinha estrutura mínima para atender às demandas educacionais da nação, de modo a colocá-la em condições de seguir o curso dos países mais avançados.

A despeito de terem sido procedidas reformas educacionais em alguns estados brasileiros, até o início dos anos 1930, não se havia tentado dar forma a um sistema educacional que pudesse atender às demandas educacionais da jovem república. Essa possibilidade emergiria após o golpe político de 1930, que levou Getúlio Vargas ao poder. É nesse contexto, dos anos de 1920 a 1930, que alguns intelectuais brasileiros destacaram-se no cenário nacional. Influenciados pelos pensamentos de Dewey e Kilpatrick, demonstravam interesse na transformação social do Brasil, defendendo que essa mudança viria por meio da educação.

Na tentativa de sinalizar uma organização para as mudanças do "novo tempo", Vargas solicitou à Associação Brasileira de Educação $(A B E)^{3}$ a elaboração de um documento com "parâmetros" que serviriam para nortear a instauração de um sistema educacional nacional, atendendo à demanda por educação.

Fernando de Azevedo é destacado para tal missão e elabora o documento que ficou conhecido como Manifesto dos Pioneiros da Educação Nova, publicado em 12 de março de 1932. Conforme sinaliza Saviani (2007), esse documento, endereçado "ao povo e ao governo", foi assinado por 26 proeminentes educadores e intelectuais da época, sendo amplamente divulgado e debatido naquele contexto.

Nesse documento, a educação foi tratada como a principal das responsabilidades de um país que desejasse avançar e acompanhar

3 Associação Brasileira de Educação (ABE) - sociedade civil sediada na cidade do Rio de Janeiro, fundada em 16 de outubro de 1924. Reunia intelectuais, educadores, políticos, escritores, jornalistas, profissionais das mais diversas áreas, que julgavam ser possivel transformar o país por meio da educação. 
as transformações (industrial, tecnológica, educacional) pelas quais o mundo passava. As bases do Manifesto de 1932, pautadas na educação democrática e progressista, liberdade de pensamento e igualdade de oportunidades, expressavam os ideais que acompanhavam essa "era do progresso".

É nesse contexto "progressista" que atuou Manoel Bergström Lourenço Filho, um dos intelectuais mais destacados do movimento reformador, considerado por Saviani como uma "[...] figura-chave no processo de desenvolvimento e divulgação das ideias pedagógicas da escola Nova no Brasil" (2007, p. 205).

\section{Manoel Bergström Lourenço Filho e sua Produção Didática}

Nascido em 10 de março de 1897, na Vila de Porto Ferreira. Primogênito, Lourenço Filho estudou, até o ano de 1914, na Escola Normal Primária de Pirassununga, ano em que se formou recebendo diploma de normalista. Após a formatura, retornou à sua cidade natal e exerceu a profissão de professor substituto no ano de 1915, mesmo ano em que começou a publicar seus primeiros escritos, atividade que desenvolveria entre 1915 e 1921, tanto em revistas como nos jornais de sua própria cidade, e também no Jornal de Piracicaba, O Estado de São Paulo e outros.

Em 1916, mudou-se para São Paulo com o propósito de dar continuidade aos estudos. Em 1917, tendo cursado o $4^{\circ}$ e último ano na Escola Normal Secundária da Capital - Escola Normal da Praça-, recebeu novo diploma de professor.

Em 1920, iniciou atividade docente na Escola Normal Primária como professor substituto de Pedagogia e Educação Cívica, onde permaneceu até 1921, quando foi eleito professor da cadeira de Psicologia e Pedagogia da escola Normal de Piracicaba, mesmo ano em que fundou, na mesma cidade, a Revista de Educação, na qual publicou seu primeiro trabalho de pedagogia intitulado Estudo da atenção escolar.
Em 1922, publicou, na Revista de Educação, seu trabalho intitulado Prática Pedagógica. Nesse mesmo ano, foi indicado pelo governo de São Paulo ao governo do Ceará, onde realizou uma grande reforma no ensino geral, registrada como "[...] um dos grandes movimentos pioneiros da Escola Nova no País" (MONARCHA, LOURENÇO FILHO, 2001, p. 29).

Em 1924, reassumiu o cargo de docente na Escola Normal de Piracicaba e, no ano seguinte, mudou-se para a capital de São Paulo para assumir o cargo de professor de Psicologia e Pedagogia na Escola Normal da Praça, tendo atuado como docente nessa instituição entre os anos de 1925 e 1930. A partir de 1926, organizou a Biblioteca de Educação ${ }^{4}$, pela editora Melhoramentos, sendo seu editor chefe até 1970 (ano de sua morte).

Foi em 1930 que publicou seu livro Introducão ao Estudo da Escola Nova, que é, conforme Saviani (2007, p. 200), "[...] o primeiro livro empenhado em divulgar o ideário renovador no Brasil, de forma sistemática [...]".

Em 1932, ano de publicação do Manifesto dos Pioneiros da Educação Nova, Lourenço Filho era membro da academia Paulista de Letras e acabara de assumir o cargo de diretor do Instituto de Educação do Distrito Federal, permanecendo nesse até 1937 e como docente de psicologia educacional até 1938.

Como escritor e respeitado intelectual de seu tempo, Lourenço Filho publicou diversas obras didáticas voltadas ao ensino primário, produção que "[...] não é menos importante nem menos significativa do que as demais" (MONARCHA, LOURENÇO FILHO, 2001, p. 132133), as quais revelam a preocupação do autor em contribuir para esse "especial problema". Mortatti (apud MONARCHA, LOURENÇO FILHO, 2001, p. 128) destaca que esse é um aspecto da obra do autor, que tem sido pouco explorado e merece novos estudos e pesquisas.

4 "[...] primeira coleção de textos de divulgação pedagógica criada no País" (MONARCHA, LOURENÇO FILHO, 2001, p. 31). 
No Quadro 1, apresenta-se a obra didática de Lourenço Filho, que abarcou do ensino primário à alfabetização de adultos.

Quadro 1 - Produção didática de Lourenço Filho

\begin{tabular}{|c|c|c|}
\hline OBRA & ANO & COMPLEMENTO \\
\hline Cartilha do povo & 1928 & $\begin{array}{l}2.200 \text { edições, com tiragem total de mais de } 25 \text { milhões } \\
\text { de exemplares, constando do catálogo da editora e } \\
\text { do Manual do Plano Nacional do Livro Didático (MEC/ } \\
\text { FAE) até } 1995 .\end{array}$ \\
\hline Pedrinho & 1953 & $\begin{array}{l}\text { Tiragem total de mais de } 2 \text { milhões de exemplares até } \\
\text { a } 18^{a} \text { edição de } 1970 .\end{array}$ \\
\hline Pedrinho e seus amigos & 1954 & $\begin{array}{l}\text { Tiragem total de mais de um milhão de exemplares até } \\
\text { a } 17^{a} \text { edição, de } 1970 .\end{array}$ \\
\hline Aventuras de Pedrinho & 1955 & $\begin{array}{l}\text { Tiragem total de mais de } 700 \text { mil exemplares até } 14^{a} \\
\text { edição, de 1970. }\end{array}$ \\
\hline $\begin{array}{l}\text { Guia do mestre: livro } 3 \\
\text { (Aventuras de Pedrinho) }\end{array}$ & 1955 & $\begin{array}{l}\text { Tiragem total de } 10 \text { mil exemplares, até a } 2^{a} \text { edição, } \\
\text { de } 1956 .\end{array}$ \\
\hline $\begin{array}{l}\text { Leituras de Pedrinho e } \\
\text { Maria Clara }\end{array}$ & 1956 & $\begin{array}{l}\text { Tiragem total de mais de } 500 \text { mil exemplares, até a } 14^{2} \\
\text { edição, de 1970. }\end{array}$ \\
\hline Upa, cavalinho! (cartilha) & 1957 & $\begin{array}{l}\text { Tiragem total de mais de } 2 \text { milhões de exemplares, até } \\
\text { a } 12^{a} \text { edição, de } 1970 .\end{array}$ \\
\hline Aprenda por si! (Série A) & 1941 & $\begin{array}{l}\text { Tiragem total de } 16 \text { mil exemplares, até a } 6^{a} \text { edição } \\
\text { de } 1953 .\end{array}$ \\
\hline Aprenda por si! (Série B) & 1942 & $\begin{array}{l}\text { Tiragem total de } 13 \text { mil exemplares, até a } 4^{a} \text { edição, } \\
\text { de } 1952 .\end{array}$ \\
\hline $\begin{array}{l}\text { Guia do mestre: para o } \\
\text { ensino da leitura - v. } 1\end{array}$ & 1953 & $\begin{array}{l}\text { Tiragem total de aproximadamente } 45 \text { mil exemplares, } \\
\text { até a } 8^{a} \text { edição, de } 1969 .\end{array}$ \\
\hline $\begin{array}{l}\text { Guia do mestre: para o } \\
\text { ensino da leitura - v. } 2\end{array}$ & 1954 & $\begin{array}{l}\text { Tiragem total de aproximadamente } 40 \text { mil exemplares, } \\
\text { até a } 6^{a} \text { edição, de } 1969 .\end{array}$ \\
\hline $\begin{array}{l}\text { Guia do mestre para a } \\
\text { cartilha Upa, cavalinho! }\end{array}$ & 1956 & Tiragem de 30 mil exemplares até a $4^{a}$ edição, de 1957. \\
\hline $\begin{array}{l}\text { Guia do mestre para o } \\
\text { ensino da leitura - } 2 \text { v. }\end{array}$ & 1968 & Com 2 edições por volume até 1969. \\
\hline $\begin{array}{l}\text { Nova tabuada e Noções } \\
\text { de Aritmética }\end{array}$ & 1958 & $\begin{array}{l}\text { Tiragem total de mais de um milhão de exemplares, } \\
\text { até a } 33^{a} \text { edição, de } 1986 .\end{array}$ \\
\hline
\end{tabular}

Fonte: Adaptado de Monarcha e Lourenço Filho (2001, p. 128)

Para as finalidades do presente trabalho, são considerados os materiais didáticos desenvolvidos para o ensino da aritmética/matemática indicados no Quadro 2:

Quadro 2 - Livros de Aritmética/Matemática de Lourenço Filho

\begin{tabular}{|c|c|l|}
\hline OBRA & ANO & COMPLEMENTO \\
\hline Aprenda por si! (Série A) & 1941 & Tiragem total de 16 mil exemplares, até a 6 ${ }^{\text {a }}$ edição de 1953. \\
\hline Aprenda por si! (Série B) & 1942 & Tiragem total de 13 mil exemplares, até a $4^{a}$ edição, de 1952. \\
\hline
\end{tabular}




\begin{tabular}{|l|c|l|}
\hline \multicolumn{1}{|c|}{ OBRA } & ANO & \multicolumn{1}{c|}{ COMPLEMENTO } \\
\hline $\begin{array}{l}\text { Nova tabuada e noções } \\
\text { de aritmética }\end{array}$ & 1958 & $\begin{array}{l}\text { Tiragem total de mais de um milhão exemplares, até a } 33^{a} \\
\text { edição, de 1986. }\end{array}$ \\
\hline $\begin{array}{l}\text { Mapas para o ensino de } \\
\text { aritmética <PARKER> } \\
\text { nas escolas primárias }\end{array}$ & 1943 & $\begin{array}{l}\text { Não foram encontrados registros de edições e anos } \\
\text { correspondentes, mas há referência até a } 12^{a} \text { edição, s.d. }\end{array}$ \\
\hline
\end{tabular}

Fonte: Adaptado de Monarcha e Lourenço Filho (2001, p. 128)

Pretende-se, neste artigo, como já enunciado, mapear e analisar as produções acadêmicas que discutem a obra didática do autor no campo da aritmética/matemática, terreno aberto para novos estudos e que só recentemente vem despertando maior interesse, conforme aponta Valente (2014, p. 63).

\section{Produção Acadêmica Sobre a Obra Didática de Lourenço Filho Para o Ensino de Aritmética/Matemática}

O levantamento das produções acadêmicas que abordam os textos didáticos produzidos por Lourenço Filho para o ensino de aritmética/matemática foi efetuado por meio das palavras-chave: Lourenço Filho, aritmética e matemática. Esse levantamento foi feito nas bases: Scientific Electronic Library Online (SciELO) e Biblioteca Digital de Teses e Dissertações - BDTD/IBICT, além do Google e Google acadêmico.
A análise dos trabalhos intenta indicar os elementos enfatizados pelos autores, sinalizar as características comuns e apreender as avaliações que tecem quanto ao caráter inédito e inovador das obras de Lourenço Filho voltadas ao ensino desse conteúdo.

Sobre a escassez desses estudos, Valente (2013, p.1) observou:

\begin{abstract}
Muito extensa é a produção de Manoel Bergström Lourenço Filho e a quantidade de referências sobre esse educador. [...] Essa imensa produção, no entanto, não mostra a existência de textos que tenham analisado as propostas elaboradas por Lourenço Filho para ensino de matemática. Propostas destinadas aos primeiros anos escolares.
\end{abstract}

Em sequência, apresentamos quadros ( 3 e 4 ) referentes aos trabalhos encontrados com base no recorte estabelecido para este estudo.

Quadro 3 - Dissertações sobre a obra didática de Lourenço

Filho para o ensino de aritmética/matemática

\begin{tabular}{|l|l|l|c|}
\hline \multicolumn{1}{|c|}{ TÍTULO } & \multicolumn{1}{|c|}{ AUTOR } & \multicolumn{1}{c|}{ PROGRAMA/INSTITUIÇÃO } & ANO \\
\hline $\begin{array}{l}\text { Manuais pedagógicos e as } \\
\text { orientações para o ensino de } \\
\text { matemática no curso primário em } \\
\text { tempos de Escola Nova }\end{array}$ & $\begin{array}{l}\text { MARQUES, } \\
\text { Josiane Acácia de } \\
\text { Oliveira }\end{array}$ & $\begin{array}{l}\text { Programa de Pós-Graduação em } \\
\text { Educação e Saúde na Infância e na } \\
\text { Adolescência, Universidade Federal } \\
\text { de São Paulo/UFSP (Guarulhos) }\end{array}$ & 2013 \\
\hline
\end{tabular}

5 Material de aritmética que foi "Reorganizado pelo Prof. Lourenço Filho". A fonte original são as Cartas de Parker, que, segundo Portela (2014, não paginado), foi um "[...] material produzido pelo professor norte-americano Francis Wayland Parker, que compreendia lições apresentadas passo a passo nas Cartas ou quadros-murais. Um dispositivo que trazia uma proposta moderna para o ensino da Aritmética nos anos iniciais de escolarização, a partir do ensino intuitivo, método que se contrapunha à tradicional memorização, repetição e abstração, práticas muito em voga desde a escola de primeiras letras, dos tempos imperiais". 


\begin{tabular}{|l|l|l|c|}
\hline \multicolumn{1}{|c|}{ TÍTULO } & \multicolumn{1}{|c|}{ AUTOR } & \multicolumn{1}{c|}{ PROGRAMA/INSTITUIÇÃO } & ANO \\
\hline $\begin{array}{l}\text { A Aritmética de Lourenço Filho: } \\
\text { um estudo sobre as dinâmicas de } \\
\text { transformações do saber escolar } \\
\text { em face de uma nova pedagogia }\end{array}$ & SOARES, Marcia & $\begin{array}{l}\text { Programa de Pós-Graduação em } \\
\text { Educação e Saúde na Infância e na } \\
\text { Adolescência, Universidade Federal } \\
\text { de São Paulo/UFSP(Guarulhos) }\end{array}$ & 2014 \\
\hline
\end{tabular}

Fonte: Google Acadêmico e Google

Quadro 4 - Artigos científicos sobre a obra didática de Lourenço

Filho para o ensino de aritmética/matemática

\begin{tabular}{|l|l|l|c|}
\hline \multicolumn{1}{|c|}{ TÍTULO } & \multicolumn{1}{|c|}{ AUTOR } & \multicolumn{1}{|c|}{ PERIÓDICO/EVENTO } & \multicolumn{1}{c|}{ ANO } \\
\hline $\begin{array}{l}\text { Lourenço Filho, as Cartas de } \\
\text { Parker e as transformações da } \\
\text { aritmética escolar. }\end{array}$ & $\begin{array}{l}\text { VALENTE, Wagner } \\
\text { Rodrigues. }\end{array}$ & $\begin{array}{l}\text { Congresso Brasileiro de História } \\
\text { da Educação. }\end{array}$ & 2013 \\
\hline $\begin{array}{l}\text { Lourenço Filho e o moderno ensino de } \\
\text { aritmética: produção e circulação de } \\
\text { um modelo pedagógico. }\end{array}$ & VALENTE, Wagner Rodrigues & $\begin{array}{l}\text { Hist. Educ., Santa Maria, v. 18, n. } \\
44, \text { p. 61-77 }\end{array}$ & 2014 \\
\hline $\begin{array}{l}\text { Lourenço Filho e a matemática da } \\
\text { Escola Nova }\end{array}$ & $\begin{array}{l}\text { VALENTE, Wagner } \\
\text { Rodrigues; BASINELO, Ieda; } \\
\text { SOARES, Marcia Guedes }\end{array}$ & $\begin{array}{l}\text { Caminhos da Educação } \\
\text { atemática em Revista - v.1, n. } 1\end{array}$ & 2014 \\
\hline
\end{tabular}

Fonte: Google e SciELO

Como se vê nos quadros expostos, encontramos poucos trabalhos que abordam a produção didática do autor para o ensino de aritmética/ matemática, a rigor somente a obra de Marcia Guedes Soares (2014) é que, de fato, aborda diretamente as cartilhas Aprenda por si! séries $A$ e $B$, de sua autoria, sendo que as demais obras mencionadas fazem referência a trabalhos que não são da lavra de Lourenço - caso das obras: Nova Tabuada e Noções de aritmética, no qual consta como "orientador"; e Mapas para o ensino de aritmética - PARKER - nas escolas primárias, reorganizada por ele.

A dissertação de Josiane Marques (2013) foi inserida neste estudo para elucidação do contexto referente à produção dos materiais produzidos para ensino de aritmética/matemática à época do fortalecimento da Escola Nova no Brasil. A autora integra o Grupo de Pesquisa de História da Educação Matemática (GHEMAT) ${ }^{6}$, que tem

6 Grupo de Pesquisa de História da Educação Matemática no Brasil, criado em 2000. Está cadastrado no diretório de Pesquisas do CNPq e tem como líderes os professores Nauza B. Pinto (PUC-PR) e Wagner R.Valente (UNIFESP, campus Guarulhos). desenvolvido pesquisas sobre essa parcela da obra do autor. Destacamos, ainda, que a busca na base BDTD/IBICT não revelou qualquer trabalho sobre a temática de maneira específica.

As dissertações foram encontradas no Google Acadêmico; já os artigos, foram selecionados a partir do uso da ferramenta de busca Google e da base SciELO.

Passamos em sequência a indicar de que maneira os trabalhos encontrados abordam a produção de Lourenço Filho voltados à aritmética/matemática.

O trabalho intitulado Manuais Pedagógicos e as orientações para o ensino de Matemática no curso Primário em Tempos de Escola Nova, de Marques, teve o objetivo de investigar as orientações prevalecentes nos manuais para o ensino de matemática utilizados no período de fortalecimento da Escola Nova no Brasil, esse estudo nos traz a clara percepção de como se formou o discurso escolanovista para o ensino desse conteúdo no início do século XX. 
Por meio da análise dos principais manuais didáticos de autores internacionais e nacionais, a autora defende que os ideais escolanovistas postulados por John Dewey, Claparéde, Ferrière, Montessori, Decroly, entre outros autores, foram disseminados na realidade brasileira (MARQUES, 2013).

Entre os manuais analisados pela autora, estão os de

[...] Edward Lee Thorndike A nova metodologia da aritmética, 1936, Margarita Comas, Metodologia de la aritmética y la geometria, 1932, Farias de Vasconcelos, Como se ensina à aritmética: didáctica, 1933 e como Como se ensina a raciocinar em aritmética: psicologia aplicada a didática, 1934, Alfredo Miguel Aguayo, Didática da Escola Nova, 1935 e, Everardo Backheuser, A aritmética na escola nova, 1933. (MARQUES, p. 39-40, grifos da autora)

Conforme conclui Marques (2013), esses manuais formaram uma espécie de "vulgata escolanovista", que em essência propunha o rompimento com práticas pedagógicas ditas tradicionais. A pesquisadora traça a trajetória intelectual de cada autor até a formulação deles, expondo os pontos de convergência entre essas produções, apontando as categorias de análises em comum - como o cálculo em multiplicação, a resolução de problemas, os problemas sem número, a metodologia de projetos e os testes matemáticos -, indicando com isso as raízes teóricas em comum, ou seja, os autores escolanovistas citados.

Todavia, ainda segundo Marques, apesar das aproximações entre os autores no que tange ao discurso, sobressai "[...] o discurso organizado por Thorndike" (2013, p. 123), cujo material produzido mostra "[...] a tentativa de comprovar a metodologia defendida [...] por intermédio de 'tests'". (MARQUES, 2013, p. 125). A autora considera que esses intelectuais insistiam "[...] na didática passo a passo das técnicas operatórias [...] ocupavam-se em orientar os educadores para a parte prática do ensino". (2013, p. 124).

Exemplo desse tipo de material são as Cartas de Parker ${ }^{7}$, modelo de manual que circulava no Brasil desde o inicio do século XX e disputava espaço com outros manuais. Esse material foi abordado por Wagner Rodrigues Valente $(2013 ; 2014)$ nos trabalhos Lourenço Filho, as Cartas de Parker e as transformacões da aritmética escolar e Lourenço Filho e o moderno ensino de aritmética: produção e circulação de um modelo pedagógico. Nesses estudos, o autor discorre e questiona sobre a permanência desse tipo de material para o ensino de aritmética, pautado nos moldes tradicionais, de vaga intuitiva, distribuído durante toda a primeira metade do século $X X$, em um momento onde o discurso por uma escola nova imperava.

Observa o autor:

[...] as Cartas de Parker são divulgadas inicialmente através da Revista de Ensino. No ano de 1902, em diferentes números dessa Revista, são colocadas à disposição do professorado 48 cartas. [...] o responsável por essa divulgação é Joaquim Luiz de Brito. Esse mesmo professor terá papel importante na oficialização desse material didático para as escolas paulistas. $(2013$, n.p.).

As cartas foram reorganizadas por Lourenço Filho e publicadas no Brasil, pela editora Melhoramentos, em $1943^{8}$ sob o título Mapas para o

7 Segundo Valente (2013, p. 4): "As Cartas de Parker constituem um conjunto de gravuras cujo fim é o de auxiliar o professor a conduzir metodicamente o ensino, sobretudo, das quatro operações fundamentais. Junto de cada gravura, há uma orientação ao professor de como deveria dirigir-se à classe de modo a fazer uso de cada uma delas e avançar no ensino da Aritmética.".

8 "Os arquivos da editora Melhoramentos indicam a publicação do material de Parker a partir de 1909. Depois de nove edições - onde não se tem a informação dos anos em que foram publicadas as levas da segunda à nona - é retomada a publicação somente em janeiro de 1943, com a 10². edição dos Mapas de Parker". (VALENTE, 2013, n.p.). 
ensino de aritmética - PARKER - nas escolas primárias. Aponta Valente que, com o sucesso das Cartas de Parker no Brasil, aquilo que inicialmente era um "[...] recurso didático, transformou-se numa referência para o ensino de Matemática, passando a constituir um modelo pedagógico a ser utilizado por todos aqueles que acompanham a modernização da pedagogia" (2014, p. 67-68).

O autor ainda pondera que os estados de Santa Catarina, Minas Gerais, Paraná, Sergipe, Rio Grande do Norte, dentre outros, acolheram o material de Parker como ícone de uma educação moderna. Chama também a atenção para a inclusão desse material na legislação escolar, mencionando-o como um [...] guia para a construção de livros didáticos [...] (VALENTE, 2014, p. 72).

Valente destaca o uso das Cartas de Parker no contexto da reforma educacional do Ceará (1922/1923) encetada por Lourenço Filho e observa que essa experiência do autor com o método intuitivo levou a que publicasse o material com algumas mudanças "engenhosas", em 1943, por meio da editora Melhoramentos, empreitada que the granjeou críticas por tratar-se de um material considerado ultrapassado para os conceitos escolanovistas.

Em finais da década de 1920 as referências paulistas perdem força em âmbito nacional. Um novo tempo surge com o movimento da Escola Nova e sua difusão diferenciada pelos estados brasileiros. No entanto, em termos do ensino de matemática, mesmo o representante mais ativo do escolanovismo - Lourenço Filho - não conseguirá dar passo adiante na mudança do ideário das lições de coisas, para o que seria o método ativo da matemática. A formação matemática do professor primário continuará a ter discursos e propostas calcadas nas Cartas de Parker ainda por longa data. (VALENTE, 2011, p. 115)

Segundo Basinelo, Valente e Soares (2014, p. 28), é a experiência docente de Lourenço
Filho com as Cartas/Mapas de Parker desde os tempos de docência no Ceará que o inclina e faz com que "[...] busque, de algum modo, 'atualizar' as orientações de uso desse material didático".

Concluem os autores que a "[...] estada de Lourenço Filho no Ceará, em termos de ensino de aritmética no curso primário, reafirma o modelo pedagógico que já vinha se espalhando pelo Brasil: o uso das Cartas de Parker" (VALENTE; SOARES, 2012, p. 27), ou seja, o método intuitivo apontado por Soares (2014) também como arte de ensinar, praticada na capital paulista.

Lourenço Filho lançou em 1941, pela editora Melhoramentos, o impresso, elaborado por ele, voltado ao ensino de aritmética, intitulado Aprenda por si! (BASINELO; VALENTE; SOARES, 2014). O trabalho encontrado, que trata diretamente da publicação mencionada, é a dissertação de mestrado da pesquisadora Marcia Guedes Soares, com o título: Aritmética de Lourenço Filho: Um estudo sobre as dinâmicas de transformações do saber escolar em face de uma nova pedagogia.

A autora sinaliza que nos debates e reformas empreendidos entre 1920-1930, a ausência de um sistema público de ensino impôs-se à intelectualidade brasileira e determinou a busca por recursos técnicos, científicos e doutrinários para a educação. De modo que a Escola Nova parecia tornar possível a implantação de uma escola de massas: seriação, classes homogêneas, ensino simultâneo, regulamentação do tempo escolar, enquadramento disciplinar, organização do espaço escolar, dentre outros; logo: "[...] o método de ensino e os materiais escolares fizeram parte do intenso debate sobre a questão política da educação popular e meios para efetivá-la". (SOARES, 2014, p. 37).

Destaca a autora que, durante esse período, Lourenço Filho, como editor chefe da Biblioteca de Educação da editora Melhoramentos, passou a exercer grande influência na construção e divulgação de novas concepções para a cultura escolar. 
Soares ressalta ainda que Lourenço Filho, "[...] atento à demanda por uma produção de materiais e técnicas para implantar um novo modelo de escola [...]" (2014, p. 30) e para dar uma resposta aos debates políticos quanto à educação popular voltados aos métodos de ensino e aos materiais escolares, lançou em 1930 a obra Introdução à Escola Nova, peça central da Biblioteca de Educação e dispositivo "[...] de uma estratégia editorial cujo objetivo é a formação de uma nova cultura pedagógica do professorado, condição de possibilidade de institucionalização de uma nova escola" (CARVALHO apud SOARES, 2014, p. 30).

Na década de 1930, em Introdução ao Estudo da Escola Nova, Lourenço Filho teceu críticas tanto ao ensino baseado em memorização como ao método intuitivo como lição de coisas. Como ciência, defendia a ação, devendo assim a técnica escolar adaptar-se a essa nova filosofia (SOARES, 2014, p. 62, grifos da autora).

Para a autora, Lourenço Filho "[...] defendeu a escola ativa e a organização racional de classes homogêneas, o ensino seletivo e diferenciado ou sob medida [...] além da classificação cientifica dos anormais de inteligência" (2014, p. 30); acrescenta ainda que sua visão de escola nova "[...] prescreve, dentre outros aspectos, [...] o interesse, que pode ser ensinado, por meio de condicionamento, sendo, para tanto, necessário fazer, fazer com necessidade". (2014, p. 90), uma das principais características da escola ativa defendida pelo autor.

A autora conclui que as características da aritmética/matemática de Lourenço Filho dada a ler em Aprenda por si! apresentam uma mistura tanto da arte de ensinar (ou ensino intuitivo), defendida por Sampaio Dória e Oscar Thompson, quanto da escola ativa, baseada em Edward Lee Thorndike, na forma em que se apresentam os exercícios com certa predominância desse último (SOARES, 2014, p. 91).

Apesar das tentativas de Lourenço Filho em estabelecer uma nova forma de ensinar, como bem conclui Soares, ele não consegue avançar em seu objetivo de estabelecer uma didática inovadora dentro dos moldes escolanovistas, que advogavam uma maior liberdade para o alunato no processo de ensino. Essa é a conclusão a que chegaram os demais autores abordados neste trabalho.

A revisão de literatura aponta que os estudos são escassos e complementares, desenvolvidos a partir da mesma perspectiva teórica, da História Cultural. Os autores citados têm elucidado aspectos da obra de Lourenço Filho e apontado novos caminhos para a pesquisa. Ainda que a obra do autor seja muito estudada, há muito por avançar, no que tange à sua obra didática.

Parecem faltar no campo acadêmico trabalhos que se aprofundem na reflexão sobre as razões materiais da incoerência entre a posição do autor, filiado ao movimento da Escola Nova, e a sua produção didática. Contraditoriamente, sua obra manteve o caráter prescritivo dos "livros de texto" da escola tradicional, tão criticados pelos escolanovistas, como Fernando de Azevedo:

O livro de texto, na escola tradicional, e - livro escolar, na educação nova, distinguem-se apenas por uma diferença fundamental de função. Ele não desaparece da escola nova, mas assume uma 'nova função', tão importante, tão larga e tão profunda, que já não bastaria, para cada matéria, o único livro: o livro de leitura, o livro de texto. Já será preciso que se multipliquem os livros sobre cada matéria, para que o escolar possa manuseá-los quando necessitar, utilizando-os como 'instrumentos de trabalho' e auxiliares, aos quais tem de recorrer para obter dados e informações, esclarecer dúvidas, recolher material de estudos e de reflexão, e 'por simples prazer', que assim o fará a crianca por própria iniciativa, quando o livro assumir, para ela o valor de mais um 'elemento de cultura', e ela possa ler, na biblioteca escolar, não o livro que se the impõe, mas de todos ao seu alcance aqueles que the agrada ler, que a interessaram, por atenderem melhor aos seus gostos, às suas tendências e às suas necessidades. (AZEVEDO, 1958, p. 198) 
Neste sentido, trazemos uma consideração de Alves que pode apontar novos rumos para a pesquisa. Com base na ciência da história, o autor sinalizou que a organização do trabalho didático da escola moderna foi delineada na obra Didática Magna de Comenius, que se mantém até os dias atuais, a despeito de todas as tentativas de superação, como aquelas realizadas pelo Movimento da Escola Nova.

Com sua proposta de ensinar tudo a todos, Comenius formulou uma resposta compativel com as condições materiais de seu tempo para baratear e universalizar os serviços escolares. Para tanto, equiparou o trabalho didático àquele desenvolvido nas manufaturas de seu tempo, assentado na divisão, objetivação e simplificação do trabalho. Essa proposição se expressa no excerto seguinte:

Agiremos à imitação do sol, se

I. Cada escola, ao menos cada classe, tiver um só professor.

II. Para cada matéria, houver um só autor.

III. Para todos aqueles que estão a assistir as lições, se dispender em comum, o mesmo trabalho.

IV. Todas as disciplinas e todas as línguas forem ensinadas com o mesmo método.

V. Todas as coisas forem ensinadas, a partir dos seus fundamentos, de modo breve e eficaz, de tal maneira que a inteligência se possa abrir como que com uma chave, e as coisas se the possam manifestar espontaneamente.

VI. Todas as coisas que por natureza são conexas forem ensinadas em conexão umas com as outras.

VII.E se todas as coisas se ensinarem gradualmente sem interrupções, de modo que todas as coisas aprendidas hoje sejam reforço das aprendidas ontem e uma preparação para as que se aprenderão amanhã.

VIII. Enfim, se, em tudo, se puser de parte as coisas inúteis. (COMÉNIO, 1996, p. 278-279)
Nesses termos, o autor propôs a escola seriada, marcada pelo ensino simultâneo executado por trabalhadores especializados, os professores, diante de um coletivo de alunos, por meio de um instrumento didático sintético que apresentasse aos estudantes

[...] tudo que é necessário de modo completo, sólido e aprimorado [...] que esses livros exponham todas as coisas de modo familiar e popular para que tornem tudo acessivel aos alunos, de modo que o entendam por si, mesmo sem qualquer professor. (COMÉNIO, 1996, p. 289).

Essa escola só se materializou efetivamente no final do século XIX, ganhando força no transcurso do século XX em resposta à crescente demanda por educação escolar.

Essas considerações podem lançar novas luzes sobre a contradição implicada na obra de Lourenço Filho que, apesar de estabelecer duras críticas às práticas do modelo escolar "tradicional", terminou por produzir livros didáticos prescritivos e diretivos voltados para o ensino coletivo em escola seriada, conferindo manutenção à proposta comeniana (LANCILLOTTI, 2017).

Basinelo, Valente e Soares (2014, p. 40), ao discorrerem sobre as características do manual Aprenda por si!, destacam "[...] a semelhança de algumas das folhas de exercícios com as Cartas de Parker", corroborando com a ideia de que não houve de fato um rompimento com o método tradicional, ainda que Soares (2014) defenda haver uma "hibridação" ou mistura do método intuitivo (presente neste material) com o método ativo, postulado pelo autor.

Valente (2014, p. 74) comenta o "alvará" conferido por Lourenço Filho ao material de Parker: em termos específicos do ensino de Matemática no curso primário, em particular do ensino da Aritmética, a distinção defendida por Lourenço Filho - entre ensino intuitivo e escola ativa - é, por ele mesmo, tornada invisivel.

Nesse mesmo sentido, Basinelo, Valente e Soares (2014, p. 41) afirmam: 
[...] a análise dos exercícios apresentados na coleção Aprenda por si! Apontam para uma permanência das orientações de Lourenço Filho para o ensino de aritmética, conforme era proposto em suas aulas da Escola Normal do Ceará no início da década de 1920. (grifo nosso).

Dessa forma, fica evidente a insistência do educador "[...] na didática passo a passo das técnicas operatórias" (MARQUES, 2013, p. 124), pois se ocupava sempre de orientar os educadores e os alunos para a parte prática do processo de ensino-aprendizagem. Como sinaliza Marques (2013), nem os alunos nem os professores escapavam dos manuais didáticos.

\section{Considerações Finais}

A Escola Nova foi movimento de alcance mundial que postulava novos princípios e práticas para a educação, atinentes com as mudanças que o mundo atravessava na virada do século XIX para o século XX com o advento da Revolução Industrial. Com críticas incisivas ao ensino prevalecente, reputado de "tradicional", defendia uma educação que colocasse o aluno no centro do processo educativo.

Manoel Bersgström Lourenço Filho foi um dos principias defensores do movimento da Escola Nova no Brasil e, baseado nesse ideário educacional, produziu uma gama de manuais didáticos tanto para leitura e alfabetização quanto para o ensino de aritmética/matemática. Neste artigo, foram abordados trabalhos acadêmicos produzidos acerca dos manuais elaborados por esse autor voltados para o ensino de aritmética/matemática nas primeiras décadas do século XX.

Ao todo foram encontrados cinco trabalhos com foco na temática elegida para a presente discussão, a saber: a dissertação de Josiane A. O. Marques (2013), intitulada Manuais Pedagógicos e as orientações para o ensino de Matemática no curso Primário em Tempos de Escola Nova, e a de Marcia Guedes Soares (2014), com o tema Aritmética de Lourenço Filho: um estudo sobre as dinâmicas de transformações do saber escolar em face de uma nova pedagogia; os artigos científicos de Wagner Rodrigues Valente, com o título Lourenço Filho, as Cartas de Parker e as transformações da aritmética escolar, de 2013, e Lourenco Filho e o moderno ensino de Aritmética: produção e circulação de um modelo pedagógico, de 2014; e, por fim, também escrito por Wagner Rodrigues Valente, em coautoria com Ieda Basinelo e Marcia Guedes Soares, de 2014, o artigo intitulado Lourenço Filho e a matemática da Escola Nova.

Nessas obras, encontramos, como já mencionado, informações sobre a trajetória de Lourenço Filho até a produção de seu material voltado ao ensino de aritmética/matemática, onde constatamos as influências de autores como Sampaio Dória e Oscar Thompsom, defensores do método intuitivo de ensino, popular até o inicio da década de 1920 no Brasil e amplamente divulgado por meio das Cartas de Parker, material que acabou se tornando mais do que um instrumental para o ensino de aritmética, e sim uma referência pedagógica que muito influenciou o ensino de aritmética/ matemática no Brasil.

Esse fato corrobora-se pelas sucessivas edições do material didático para o ensino de aritmética/matemática, de autoria de Lourenço Filho ou avalizadas por ele, publicadas pela editora Melhoramentos durante sua atuação como editor chefe (até sua morte em 1970), e mesmo depois. Apesar das críticas recebidas em virtude da aprovação da circulação desses livros didáticos, Lourenço Filho não somente autoriza a circulação, como assina a orientação ou reorganização dos manuais: Nova tabuada e Noções de Aritmética e Mapas para o ensino de aritmética - PARKER - nas escolas primárias, respectivamente, creditando ao material ainda maior autoridade, em pleno movimento da Escola Nova, que criticava frontalmente os manuais didáticos prescritivos

Essa situação demonstra em essência o cerne do que buscamos apontar neste estudo, a saber: a divergência encontrada na produção didática elaborada ou divulgada por Lourenço 
Filho para o ensino da aritmética/matemática, com o ideário escolanovista abraçado por ele. Nos trabalhos abordados, encontramos análises que corroboram com esse entendimento, entretanto, não avançam na compreensão dos motivos que estão por detrás dessa incoerência.

A conclusão a que se chega é que, apesar das aproximações entre as obras analisadas, por fim, acabam por esbarrar na questão basilar do que postula Alves (2005, 2011), de que a escola moderna é tributária da organização do trabatho didático proposta por Comenius, no século XVII, na sua Didática Magna para a educação de todos os homens e que, conforme ratifica Lancillotti (2017), apesar das tentativas em mudar o foco do processo educativo, do professor para o aluno, atentando para sua individualidade, Lourenço Filho contraditoriamente acabou se destacando como autor de instrumentos didáticos homogêneos, "[...] a despeito de todo discurso em contrário, a proposta de Lourenço Filho não toca organização manufatureira do trabalho" e não vai além de "substituir uma rotina por outra" (LANCILLOTTI, 2017, p. 11).

A questão que ganha destaque a partir do estudo é a urgência por compreender historicamente a manutenção dos manuais didáticos, material homogêneo, fragmentado, prescritivo, que não dá acesso real ao saber historicamente acumulado pela humanidade. $O$ entendimento dessa questão é base para sua superação de modo que o conhecimento possa ser efetivamente universalizado.

\section{Referências}

ALVES, G. L. O trabalho didático na escola moderna: formas históricas. Campinas, SP: Autores Associados, 2005.

A Produção da Escola Pública Contemporânea. 2 ed. Campinas, SP; Autores Associados. Campo Grande, MS: UFMS, 2004.

AZEVEDO, F. A educação e seus problemas. 4. ed. São Paulo: Edições Melhoramentos. 1958, t.1, v.8.
BASINELO, I; SOARES, M. G.; VALENTE, W. R. Lourenço filho e a matemática da Escola Nova. Caminhos da Educação Matemática em Revista. v. 1, n. 1, 2014.

CAMBI, F. História da Pedagogia. São Paulo: Ed. UNESP, 1999.

COMÉNIO, J. A. Didáctica Magna: tratado da arte universal de ensinar tudo a todos. 4. ed. Lisboa: Calouste Gulbekian, 1996.

EDIÇÕES MELHORAMENTO. Nova Tabuada e Noções de Aritmética. (Orientação do Prof. Lourenço Filho). São Paulo: Melhoramentos, s/d.

Mapas para o ensino de aritmética PARKER - nas escolas primárias. (Reorganizada pelo Professor Lourenço Filho). 12. ed. São Paulo: Melhoramentos, s/d.

IVASHITA, S. B.; VIEIRA, R. A. Os Antecedentes do Manifesto dos Pioneiros da Educação Nova (1932). VIII Seminário Nacional de Estudos e Pesquisas "História, Sociedade e Educação", 2009. Disponível em: <http://www. histedbr.fe.unicamp.br/acer_histedbr/seminario/seminario8/_files/GuEVnTfr.pdf>. cesso em: ago. 2016.

KILPATRICK, W. H. Educação para a civilização em mudança. São Paulo: Edições Melhoramentos, 1977.

LANCILLOTTI, S. S. P. Escola Nova, Instrumentos Tradicionais: a produção didática de Manoel Bersgtrom Lourenço Filho em discussão. Revista HISTEDBR On-line, v. 17, n. 71. Campinas, mar. 2017. Disponivel em: <https:// periodicos.sbu.unicamp.br/ojs/index.php/histedbr/article/view/8649860/16288> Acesso em: jul. 2018.

LOURENÇO FILHO, Manoel Bergström, Aprenda por si! Série A. São Paulo: Editora Melhoramentos, 1941.

Aprenda por si! Série B. São Paulo: Editora Melhoramentos, 1942. 
MANIFESTO dos pioneiros da educação nova Disponivel em: <http://www.pedagogiaemfoco. pro.br/heb07.htm>. Acesso em: 19 set.2016.

MARQUES, J. A. de O. Manuais Pedagógicos e as orientações para o ensino de matemática no curso primário em tempos de Escola Nova. 2013. Dissertação (Mestrado em Educação e Saúde na Infância e na Adolescência) - Escola de Filosofia, Letras e ciências Humanas, Universidade Federal de São Paulo, Guarulhos, 2013.

MONARCHA, C.; LOURENÇO FILHO, R. Por Lourenço Filho: uma bibliografia. Brasília: INEP/MEC, 2001.

PORTELA, M. S. As cartas de Parker na matemática da escola primária paranaense na primeira metade do século XX: circulação e apropriação de um dispositivo didático pedagógico. 2014189 f. Tese (Doutorado em Educação) - Pontifícia Universidade Católica do Paraná, Curitiba, 2014. Disponível em: <https:// repositorio.ufsc.br/handle/123456789/128465>, Acesso em: 20 jul. 2017.
SAVIANI, D. História das Ideias Pedagógicas no

Brasil. Campinas: autores associados, 2007.

SOARES, M. G. A Aritmética de Lourenço

Filho: um estudo sobre as dinâmicas de transformações do saber escolar em face de uma nova pedagogia. 2014. 107 f. Dissertação (Mestrado em Educação e Saúde na Infância e na Adolescência) - Escola de Filosofia, Letras e ciências Humanas, Universidade Federal de São Paulo, Guarulhos, 2014.

TEIXEIRA, A. A Pedagogia de John Dewey. In: DEWEY, J. Vida e Educação. 4. ed. São Paulo: 1954

VALENTE, Wagner Rodrigues. Lourenço Filho e o moderno ensino de aritmética: produção e circulação de um modelo pedagógico. Hist. Educ., Santa Maria, v. 18, n. 44, p. 61-77. dez. 2014. Disponivel em: <http:// www.scielo.br/scielo.php?script=sci_arttext\&pi$d=S 2236-34592014000300005 \& \operatorname{lng}=$ en\& $\& r m=i s o>$. Acesso em: 21 abr. 2016. 